29

\title{
Using Skills Portfolios in Fourth-Year University Transition to Work Courses
}

\author{
Janet Z-K Wolstenholme \& Fred Evers \\ University of Guelph
}

'Transition from school to work' courses are an excellent way to help fourth-year university students as they complete their studies and prepare for the world of work. In this paper we present The Bases of Competence (Evers, Rush, \& Berdrow, 1998), a model of the advanced skills used by university graduates in the workplace. The model consists of four groupings of skills (base competencies): Managing Self, Communicating, Managing People and Tasks, and Mobilizing Innovation and Change. Each base competency consists of four or five more specific advanced skills (e.g., Mobilizing Innovation and Change consists of ability to conceptualize, creativity, risk-taking, and visioning). The base competencies and the skills within each base serve as the core of the skills that make up the skills portfolios students complete in the transition courses conducted at the University of Guelph and the University of Guelph-Humber. Students reflect on and report behaviours related to each skill based on their education, life, and work experiences. The portfolio also includes a résumé, cover letter, and other elements related to career development and work search. The portfolio comprises fifty percent of the course; the remainder is taken up with a project and presentation aimed at capping the student's undergraduate experience with eyes to the future and enhancing under-utilized oral communication skills. ${ }^{1}$

\section{Introduction}

$\mathrm{T}$ his paper is about a fourth-year university capstone course implemented at the University of

Guelph and the University of Guelph-Humber. A capstone course should assist students in the transi-

\footnotetext{
1 The research undertaken by Evers, Rush, \& Berdrow (1998) has since been reinforced by further research conducted by Evers, Power, \& Mitchell (2003) in Preparing for the Future: Identifying Advanced Essential Skills Needs in Canada, again finding that leadership and creativity were skills most in demand in the workplace.
} 
tion to the next stage of their life by 'capping' or concluding their undergraduate experience. This can be achieved by including two aspects to course material - synthesis and reflection. Synthesis allows students the opportunity to work on something that encompasses what they have learned throughout their academic career. In our case, students work on a project and integrate theories, methods, and research from their discipline. Depending on the size of the class, students work either in groups or alone. The course at the University of Guelph is capped at 35 students whereas the class at the University of Guelph-Humber has about 70 registrants. The second aspect, reflection, is just as important if not moreso in the student's transition to the next phase of life and is what we focus on in this paper. Students need an assignment or other reflective exercise in order to realize what learning has taken place and how they have grown intellectually. Reflection also enables students to prepare themselves for the workplace by identifying and matching suitable skills and other qualities ready for the work search and ensuing behaviourally based interviews. This connects the world of learning to the world of work.

Students have freedom of choice with the project undertaken in the course. Many choose to examine their intended profession from a very practical point of view. Investigating the realities of the day-today aspects of the job, some interview incumbents for the 'inside story.' The only proviso is that the paper be written like a journal article and include review of literature, research, theories, and methods appropriate to the discipline. The most recent iteration of the course at the University of Guelph-Humber instigated an electronic peer review system designed for group feedback, and a chance to amend the article before the final grade is assigned. Using this system, students get the chance to experience the academic publishing peer review process, albeit in a reduced format.

Students then present their findings to the class in the latter part of the course, and as creativity is a skill found to be in demand in the research, we encourage presentations to be as creative as possible. Creativity is also a criterion that is marked for, both in the presentation and the skills portfolio.

\section{Portfolio Format}

The majority of the course evaluation is taken up with the skills portfolio. Students use a three-ring binder and section dividers for their work. Contents include:

- a personal mission statement;

- intellectual autobiography;

- a résumé (in different formats);

- cover letters;

- record of job interviews;

- evidence of skill development within the base competencies and skills (discussed with the research after the other elements that make up the portfolio);

- development of specific skills;

- summary of strengths and areas needing development; and

- resources (can be anything the student deems relevant).

\section{Personal mission statement}

The personal mission statement is a one sentence or one paragraph statement of what the students intend to do in or with their working career. Some tie the statement to their philosophy of life and intended life's work. Others take a less esoteric approach. We use a method for ascertaining mission statements set forward in Laurie Beth Jones's book The Path (1996).

\section{Intellectual autobiography}

Students have three to five pages in which to write their intellectual journey thus far. This document serves as a great introduction to the portfolio along with the personal mission statement as well as serving as a good grounding reflection exercise. Students can go back as far as they wish. Some include learning that took place as they began formal education, some in high school, and some tie in informal learning experiences beginning their narrative in their undergraduate years. 


\section{Résumé, cover letters, and a record of job interviews}

This section contains several different types and formats of résumés and a couple of cover letters (either fictitious or real), plus a list of job interviews. We devote one class to an interview workshop where students have the chance to be on both sides of the interviewing table. Students are able to practise interviewing skills in a non-threatening environment and reflect on performance from both an interviewer and interviewee.

\section{Specific skills}

In this section, students document skills that are not covered in the base competencies, for example, skills that are specific to their program of study, proficiency in foreign languages, music, sports, use of computer programs (MS Word, Excel, PowerPoint), etc.

\section{Areas of strengths and areas needing development}

This section is a summary of the 'evidence' sections. Students highlight their strengths and note plans to develop weaker skills.

\section{Skills}

The portfolio uses The Bases of Competence as a framework, based on the "Making the Match" research conducted by Evers, Rush, \& Berdrow (1998). Discussed next is the research and skills that were found through the research and make-up the bulk of the skills portfolio. The students write reflections of behaviours that show their skill development in each skill area and include 'evidence' of skill development (more about this under "Base competency and skills' definitions").

\section{"Making the match" research}

In 1986, 20 of the Corporate Higher Education Forum's corporate members and five of its university members agreed to have their organizations participate in phase two of the "making the match" project. The participants, representing five career stages: 1) early university, 2) pre-graduate, 3) job entry, 4) job change, and 5) stabilized career, were surveyed first in $1987 / 88$, and again in $1988 / 89$ and $1989 / 90$. A total of 1,610 respondents completed all three questionnaires.

A set of 18 skills form the heart of the questionnaires completed by students, graduates, and managers. The students and graduates were asked to assess themselves and managers assessed university graduates working in their departments. The skill inventory was analyzed to determine if any logical groupings within the 18 skills exist. Four distinct combinations emerged which were found to be consistent with the evolving literature on skills and which capture the current bases of competence necessary to work in today's workplace: 1) Mobilizing Innovation and Change: ability to conceptualize, creativity/innovation/ change, risk-taking, and visioning; 2) Managing People and Tasks: coordinating, decision-making, leadership/influence, managing conflict, and planning/organizing; 3) Communicating: interpersonal, listening, oral and written communication; and 4) Managing Self: learning, personal organization/time management, personal strengths, and problem solving/analytic. Interestingly, technical skills did not group with any of the four base competencies; though clearly important to today's workplace, it was felt that computing and other technical skill areas should be dealt with as a distinct skill set.

\section{Base competency and skills' definitions}

Definitions of each skill within each base competency are presented in the course (Evers, Rush, \& Berdrow, 1998). These are the skills and definitions students work with when writing their reflections. They also gather 'evidence' to support their writing and include it in the portfolio. The evidence can be awards, papers, letters of commendation, experiences in volunteer and paid jobs, projects, websites, etc. The evidence is intended to reinforce the written reflection (about one page) where the students discuss their abilities in each skill area.

Mobilizing innovation \& change - conceptualizing, as well as setting in motion, ways of initiating and managing change that involve significant departures 
from current mode.

- Ability to conceptualize - involves the ability to combine relevant information from a number of sources, to integrate information into more general contexts, and to apply information to new or broader contexts.

- Creativity/innovation/change - involves the ability to adapt to situations of change, at times it involves the ability to initiate change, and provide 'novel' solutions to problems. Also involves the ability to re-conceptualize roles in response to changing demands related to the firm's success.

- Risk-taking - involves taking reasonable jobrelated risks by recognizing alternative or different ways of meeting objectives, while at the same time recognizing the potential negative outcomes and monitoring the progress toward the set objectives.

- Visioning - involves the ability to conceptualize the future of the company and to provide innovative paths for the company to follow.

Managing people \& tasks - accomplishing the tasks at hand by planning, organizing, coordinating, and controlling both resources and people.

- Coordinating - involves being able to coordinate the work of peers and subordinates and encourage positive group relationships.

- Decision-making - involves making timely decisions on the basis of a thorough assessment of the short- and long-term effects of decisions, recognizing the political and ethical implications, and being able to identify those who will be affected by the decisions made.

- Leadership/influence - involves the ability to give direction and guidance to others and to delegate work tasks to peers and subordinates in a manner which proves to be effective, and motivates others to do their best.

- Managing conflict - involves the ability to identify sources of conflict between oneself and others, or among other people, and to take steps to overcome disharmony.

- Planning \& organizing - involves being able to determine the tasks to be carried out toward meeting objectives (strategic and tactical), perhaps assigning some of the tasks to others, monitoring the progress made against the plan, and revising a plan to include new information.

Communicating - interacting effectively with a variety of individuals and groups to facilitate the gathering, integrating, and conveying of information in many forms (e.g., verbal, written).

- Interpersonal - involves working well with others (superiors, subordinates, and peers), understanding their needs and being sympathetic with them.

- Listening - involves being attentive when others are speaking, and responding effectively to others' comments during a conversation.

- Oral communication - involves the ability to present information verbally to others, either one-on-one or in groups.

- Written communication - involves the effective writing of formal reports and business correspondence, as well as informal notes and memos.

Managing self - constantly developing practices and internalizing routines for maximizing one's ability to deal with the uncertainly of an ever-changing environment.

- Learning - involves the ability to gain knowledge from everyday experiences and to keep up-to-date on developments in their field.

- Personal organization/time management - involves managing several tasks at once, being able to set priorities and to allocate time efficiently in order to meet deadlines.

- Personal strengths - comprises a variety of personal traits which assist individuals in dealing 
with day-to-day work situations. Some examples include: maintaining a high energy level; motivating oneself to function at optimal level of performance; functioning in stressful situations; maintaining a positive attitude; ability to work independently, and responding appropriately to constructive criticism.

- Problem solving/analytic - consists of identifying, prioritizing and solving problems; individually or in groups. Involves the ability to ask the right questions, sort out the many facets of a problem, and contribute ideas as well as answers regarding the problem.

\section{Research Results}

The overall ratings by students, graduates, and managers are between 'high' and 'average' on a five point scale (very high to very low) for all the skills, and hence, the base competencies. Within this range, there are interesting differences. Communicating and Managing Self are consistently rated higher than Mobilizing Innovation and Change and Managing People and Tasks. New hires (job entry group) consistently give themselves lower Mobilizing Innovation and Change and Managing People and Tasks scores than the other groups and rate themselves higher on the other two bases.

Respondents were also asked which skills they felt would be in greatest demand in the future and which ones must be improved. Visioning, creativity, and risk-taking from within the Mobilizing Innovation and Change base were felt to be in the highest demand in the future (and yet were rated the lowest in terms of competence). Also, leadership and managing conflict from the Managing People and Tasks base were viewed as critical skills for university graduates in corporate employment. When asked which of the 18 skills were most in need of improvement, leadership ranked first.

\section{Skills in demand}

These rankings are based on the response to "most important areas needing development."
Areas students would like to see more emphasis in university:

1. Creativity/Innovation

2. Oral Communication

3. Managing Conflict

4. Leadership

Areas graduates feel could use some improvement:

1. Leadership

2. Creativity/Innovation

3. Managing Conflict

4. Time Management

Areas managers feel employees need to develop:

1. Leadership

2. Managing Conflict

3. Visioning

4. Creativity/Innovation

The core set of skills that emerged were: in Mobilizing Innovation \& Change, visioning, creativity and risk-taking; and in Managing People \& Tasks, leadership and managing conflict. These skills were found to be rated relatively lower in terms of graduates' and employees' competence, felt to be in the greatest need of improvement, and in the greatest demand in the future by managers.

\section{Conclusion}

Students taking the 'transition' courses at the University of Guelph and The University of Guelph-Humber are able to synthesize and reflect on their academic experience based on a framework, The Bases of Competence, which has been found valuable and viable in the workplace. In addition, students begin the career development process and ready themselves for the world of work and their future careers both by the skills portfolio and with their project.

\section{References}

Evers, F.T., Power, P., \& Mitchell, J. (2003). Preparing for the future: Identifying advanced essen- 
tial skills needs in Canada: Highlights of current literature. Advanced Essential Skills Project Steering Committee.

Evers, F.T., Rush, J.C., \& Berdrow, I. (1998). The Bases of competence: Skills for lifelong learning or employability. San Francisco: Jossey-Bass.

Jones, L.B. (1996). The path: Creating your mission statement for work and for life. New York: Hyperion.

\section{Biographies}

Janet Z-K Wolstenholme is an Educational Developer in Teaching Support Services at the University of Guelph, Ontario, where she earned both her Baccalaureate and Masters degrees. She also holds a diploma in art from the Ontario College of Art and Design and a Career Development Practitioner certificate from Conestoga College. Janet's scholarly interests are in the area of entrepreneurship, career development, and visual culture.

Fred Evers is the Director of Teaching Support Services, and a Professor in Sociology \& Anthropology at the University of Guelph, Ontario. He received his Bachelor of Science in rural sociology at Cornell University and his master's and doctorate degrees in sociology at Iowa State University. His research interests include workplace skills, organizational change, and leadership. 